\section{Spectroscopic Evidence for Pseudorotation of Seven-Membered Chalcogen Rings in Solution [1]}

\author{
Ralf Steudel*, Maria Papavassiliou, and
} Detlef Jensen

Institut für Anorganische und Analytische Chemie, Technische Universität Berlin,

D-1000 Berlin 12, FRG

Konrad Seppelt

Institut für Anorganische und Analytische Chemie, Freie Universität Berlin,

D-1000 Berlin 33, FRG

Z. Naturforsch. 43b, 245-247 (1988);

received October $7 /$ October 12,1987

${ }^{77}$ Se NMR Spectra, Raman Spectra,

Elemental Sulfur, Selenium Sulfides

The ${ }^{77} \mathrm{Se}$ NMR spectrum of $1,2-\mathrm{Se}_{2} \mathrm{~S}_{5}$ exhibits one singlet at $1077.3 \mathrm{ppm}$ indicating pseudorotation in solution; the same conclusion is reached from the solution Raman spectrum of $S_{7}$ showing characteristic line broadening compared to the solid state spectrum.

The homocyclic $\mathrm{S}_{7}$ molecule is a constituent of gaseous and liquid elemental sulfur, of solidified liquid sulfur, of irradiated sulfur solutions, and of many chemically prepared sulfurs [2]. Evidence for pseudorotation of $S_{7}$ in the vapor phase at elevated temperatures has first been derived from the molar entropy calculated by statistical methods; the calculated and experimental values agree only when pseudorotation is postulated [3]. Later the height of the torsional barrier of SS bonds in sulfur rings has been estimated from the heat of formation of $S_{7}$ as $\leqslant 24 \mathrm{~kJ} / \mathrm{mol}$ [4] which would result in pseudorotation at $20^{\circ} \mathrm{C}$. We now report direct evidence for pseudorotation of seven-membered chalcogen rings at room temperature by which process all ring atoms become equivalent within a certain time interval due to a simultaneous rotation (torsion) about several of the ring bonds.

The chair-like heterocycle $1,2-\mathrm{Se}_{2} \mathrm{~S}_{5}$ according to its Raman spectrum has two neighboring Se atoms in positions 4 and 6 of Fig. 1 resulting in non-equivalent selenium atoms [5]. We have now prepared chromatographically pure $1,2-\mathrm{Se}_{2} \mathrm{~S}_{5}$ from titanocene pentasulfide and $\mathrm{Se}_{2} \mathrm{Cl}_{2}$, and recorded the ${ }^{77} \mathrm{Se} \mathrm{NMR}$

\footnotetext{
* Reprint requests to Prof. Dr. R. Steudel.

Verlag der Zeitschrift für Naturforschung, D-7400 Tübingen 0932/0776/88/0200-0245/\$ 01.00/0
}

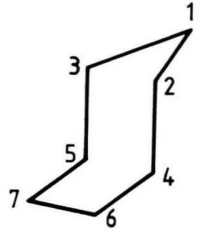

Fig. 1. Molecular structure of the chalcogen rings $S_{7}[6 a]$ and $1,2-\mathrm{Se}_{5} \mathrm{~S}_{2}[6 \mathrm{~b}]$ and most probably also of $1,2-\mathrm{Se}_{2} \mathrm{~S}_{5}[5]$.

spectrum in $\mathrm{CS}_{2}$ solution (natural abundance of ${ }^{77} \mathrm{Se}$, Jeol FX90Q spectrometer, $17.03 \mathrm{MHz}, 6 \mu$ s pulse width). After $2 \mathrm{~h}$ ( $c a$. 20,000 scans) the spectrum showed only one peak at $1077.3 \mathrm{ppm}\left[\left(\mathrm{CH}_{3}\right)_{2} \mathrm{Se}\right.$ ext. standard]; see Fig. 2. No other signal was observed in the range $1235-65 \mathrm{ppm}$. We therefore assign the

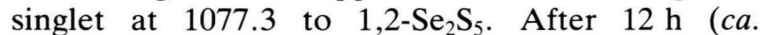
120,000 scans) three additional peaks at 784.5 , 653.4 , and $559.9 \mathrm{ppm}$ with an approximate intensity ratio of $1: 2: 1$ were observed (see Fig. 2). HPLC analysis of this solution showed the presence of $\mathrm{SeS}_{5}$ and $1,2,3-\mathrm{Se}_{3} \mathrm{~S}_{5}$ in addition to $1,2-\mathrm{Se}_{2} \mathrm{~S}_{5}$ as the only species [5]. The six-membered ring $\mathrm{SeS}_{5}$ previously not observed by NMR and the eight-membered ring $1,2,3-\mathrm{Se}_{3} \mathrm{~S}_{5}$ result from disproportionation of $1,2-\mathrm{Se}_{2} \mathrm{~S}_{5}$ according to equation (1) [5].

$$
21,2-\mathrm{Se}_{2} \mathrm{~S}_{5} \rightarrow \mathrm{SeS}_{5}+1,2,3-\mathrm{Se}_{3} \mathrm{~S}_{5}
$$

The ${ }^{77} \mathrm{Se}$ NMR spectrum of $1,2,3-\mathrm{Se}_{3} \mathrm{~S}_{5}$ is known [7] (signals at 654 and $561 \mathrm{ppm}$, intensity ratio 1:2); consequently we assign the peaks at 653.4 and $559.9 \mathrm{ppm}$ to $1,2,3-\mathrm{Se}_{3} \mathrm{~S}_{5}$ and the remaining peak at $784.5 \mathrm{ppm}$ to $\mathrm{SeS}_{5}$. The intensity ratio fits equation (1).

The NMR signals of $\mathrm{SeS}_{5}$ and $1,2-\mathrm{Se}_{2} \mathrm{~S}_{5}$ do not coincide with the signals of 14 eight-membered rings of type $\mathrm{Se}_{n} \mathrm{~S}_{8-n}(n=1 \cdots 8)$ which have been found in the region 560-729 ppm [7]. It should therefore be possible to detect six- and seven-membered selenium sulfide rings even in the presence of a large excess of $\mathrm{Se}_{n} \mathrm{~S}_{8-n}$ molecules as in extracts of quenched melts of the two elements.

Our spectra show that in solution the Se atoms of $1,2-\mathrm{Se}_{2} \mathrm{~S}_{5}$ are magnetically equivalent on the NMR time scale which can only be understood assuming pseudorotation. It seems very unlikely that in solution the Se atoms just move to the equivalent positions 6 and 7 (see Fig. 1) but after crystallization are found again only in positions 4 and 6 . Therefore, we conclude that pseudorotation of the entire ring takes place thus averaging also the two different Se positions.

To further demonstrate the pseudorotation of seven-membered chalcogen rings at $20^{\circ} \mathrm{C}$ we have recorded the Raman spectrum of $\mathrm{S}_{7}$ dissolved in $\mathrm{CS}_{2}$ 

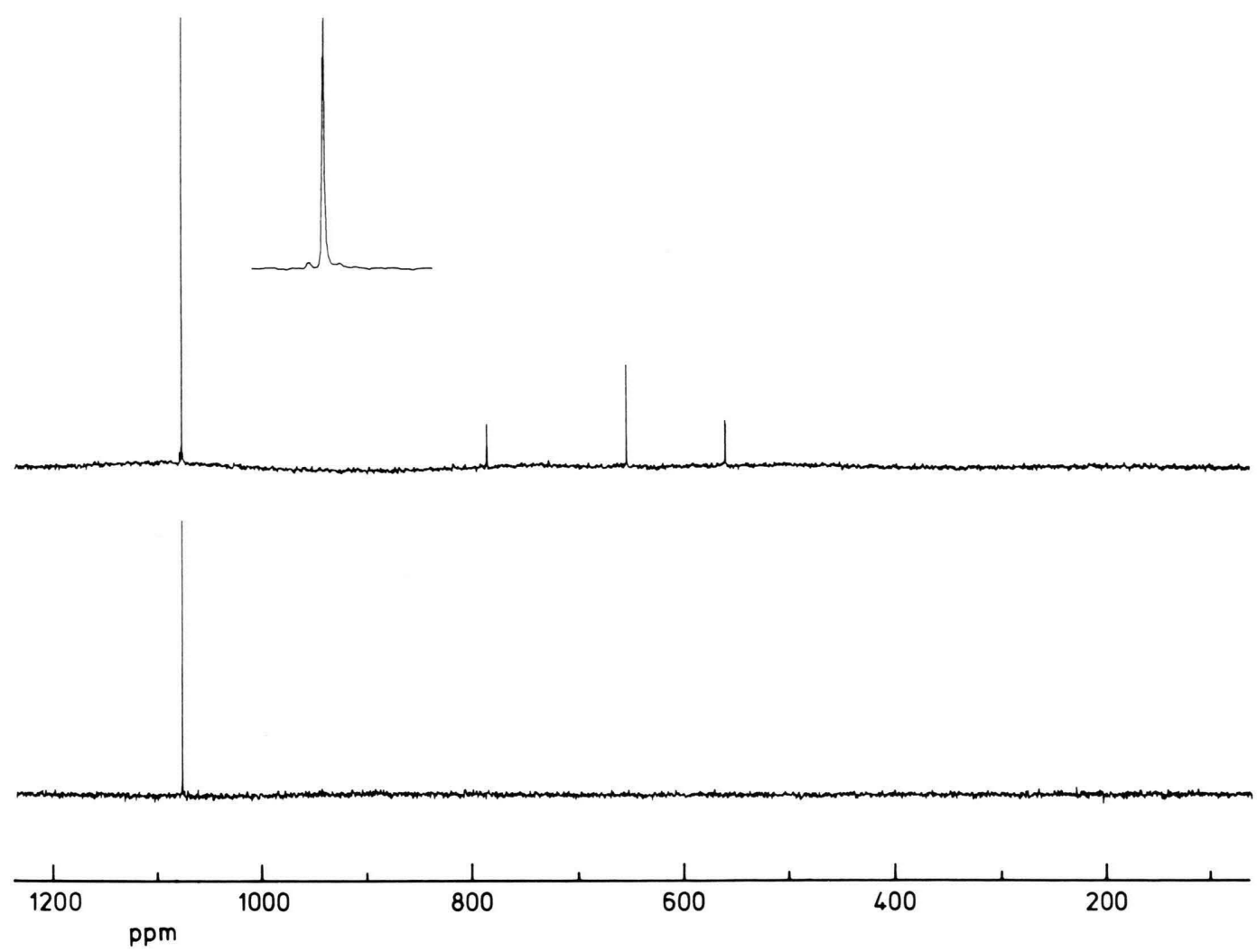

Fig. 2. ${ }^{77} \mathrm{Se}$ NMR spectra of freshly dissolved 1,2- $\mathrm{Se}_{2} \mathrm{~S}_{5}$ in $\mathrm{CS}_{2}$ (bottom) and of the same solution measured with data accumulation for $12 \mathrm{~h}$ and showing the decomposition products $\mathrm{SeS}_{5}(784.5 \mathrm{ppm})$ and $1,2,3-\mathrm{Se}_{3} \mathrm{~S}_{5}(653.4$ and $559.9 \mathrm{ppm})$ in addition (top). The two small satellites of the $\mathrm{Se}_{2} \mathrm{~S}_{5}$ signal (see inset) have been identified as spinning side bands.

and compared it to the published solid state spectrum [3] (see Fig. 3). Pseudorotation is known to influence the half-widths of certain stretching modes dramatically due to coupling with low lying torsional modes and in particular due to the splitting of vibrational energy levels of the double minimum potential resulting in a number of allowed transitions of very similar energy (see the analyses for cyclopentane [8] and cycloheptane [9] and their derivatives). In solution the expected closely neighboring lines are not resolved and broad Raman signals will result. The spectra in Fig. 3 show that the half-width of the two SS stretching modes of $S_{7}$ near 360 and $400 \mathrm{~cm}^{-1}$ increases from 8 and $4 \mathrm{~cm}^{-1}$, respectively, in solid $\mathrm{S}_{7}$ to 24 and $31 \mathrm{~cm}^{-1}$, respectively, for the $\mathrm{CS}_{2}$ solution. On the other hand, the half-width of the totally symmetrical bending mode at $239 \mathrm{~cm}^{-1}$ although split into two lines in the solid state does not differ significantly in the two spectra indicating that neither temperature nor collisional (relaxation time) effects are responsible for the broad Raman lines in the solution spectrum. Pseudorotation therefore provides the best if not the only explanation.

Financial support by the Deutsche Forschungsgemeinschaft and the Verband der Chemischen Industrie is gratefully acknowledged. 


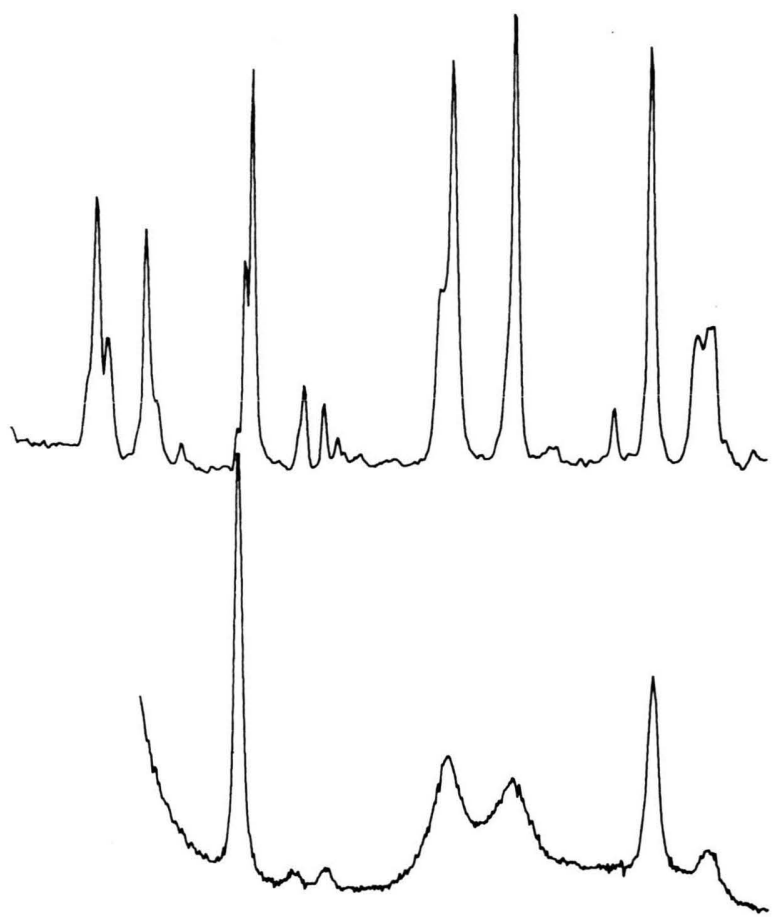

$100 \quad 150 \quad 200 \quad 250 \quad 300 \quad 350 \quad 400 \quad 450 \quad 500 \quad 550 \quad 1 / \mathrm{cm}$
Fig. 3. Raman spectra of crystalline $\mathrm{S}_{7}$ at $-100{ }^{\circ} \mathrm{C}$ (top, slit widths $1.9 \mathrm{~cm}^{-1}$ ) and of $\mathrm{S}_{7}$ dissolved in $\mathrm{CS}_{2}$ at $20^{\circ} \mathrm{C}$ (bottom, slit widths $3.19 \mathrm{~cm}^{-1}$ ) recorded using $647.1 \mathrm{~nm}$ laser excitation (ISA Raman spectrometer with double monochromator [10]).
[1] Sulfur Compounds, Part 113; for Part 112 see R. Steudel, Th. Göbel, and G. Holdt, Z. Naturforsch. 43b, 203 (1988).

[2] R. Steudel, Elemental Sulfur and Related Homocyclic Compounds and Ions, in A. Müller and B. Krebs (eds): Sulfur - The Significance for Chemistry, for the Geo-, Bio- and Cosmosphere and Technology, p. 3-37, Elsevier, Amsterdam (1984); Top. Curr. Chem. 102, 149 (1982).

[3] R. Steudel and F. Schuster, J. Mol. Struct. 44, 149 (1978).

[4] R. Steudel, Z. Naturforsch. 38b, 543 (1983).

[5] R. Steudel and E.-M. Strauss, Angew. Chem. 96, 356 (1984); Angew. Chem., Int. Ed. Engl. 23, 362 (1984).

[6] a) R. Steudel, J. Steidel, J. Pickardt, F. Schuster, and R. Reinhardt, Z. Naturforsch. 35 b, 1378 (1980); b) R. Steudel, M. Papavassiliou, E.-M. Strauss, and R. Laitinen, Angew. Chem. 98, 81 (1986); Angew. Chem., Int. Ed. Engl. 25, 99 (1986).

[7] R. Laitinen and T. Pakkanen, Inorg. Chem. 26, 2598 (1987); J. Chem. Soc. Chem. Commun. 1986, 1381.

[8] C. Rafilipomanana, D. Cavagnat, R. Cavagnat, J. C. Lassegues, and C. Biran, J. Mol. Struct. 127, 283 (1985); C. Rafilipomanana, D. Cavagnat, and J. C. Lassegues, J. Míoi. Struct. 129, 215 (1985); T. Shimanouchi, J. Chem. Phys. 47, 5018 (1967).

[9] D. F. Bocian and H. L. Strauss, J. Am. Chem. Soc. 99, 2866, 2876 (1977); D. F. Bocian, H. M. Pickett, T. C. Rounds, and H. L. Strauss, J. Am. Chem. Soc. 97, 687 (1975).

[10] For details of the Raman equipment see R. Steudel and B. Holz, Z. Naturforsch. 42b, 691 (1987). 
Nachdruck - auch auszugsweise - nur mit schriftlicher Genehmigung des Verlages gestattet Satz und Druck: Allgäuer Zeitungsverlag GmbH, Kempten 